\title{
TRAINING STRATEGY FOR THE TRANSITION PERIOD USING CROSS METHOD TO MAINTAIN PHYSICAL LEVEL AND BODYWEIGHT OF A JUNIOR WRESTLER.
}

\author{
Dr. Belal Morsy Mohammed Witwit ${ }^{1}$
}

\section{INTRODUCTION \& RESEARCH PROBLEM}

Annual course contains all elements of sports training, where composition of these elements changes according to nature of goals required to be achieved in each time period during the year. The annual plan is determined by training elements that change and transform in terms of volumes, intensities and nature of composition, according to various training periods. (9:154)

Scientists have agreed to divide a training season into three training periods. The first of them is preparation with its different stages, the second is competition period and the third is the transition one.

The transition period is considered one of the important stages of a season in training process, however, it has suffered from a lot of neglect while planning for sports training programs and its implementation, by both coaches and players, although of its contribution to sporting-level development. In fact, this neglect completely conflicts with principles of sports training in terms of continuity and strategy.

The transition period aims to restore recovery of vital organs of a player, from the effect of extreme physical and nervous exertion of training loads for both periods of preparation and competition, in addition to upgrading kinetic features and reducing physical level of a player, with the relative retention of training status, so as for a player to guarantee an optimal readiness for the next season. (8:123)

Dietrich Harre (2001) refers to a transition period as a bridge connecting the end of competition period to the start of a new preparation period. It aims to get rid of effects of overload during the previous period and qualify the body to assimilate the next training doses. It is also a bridge connecting between two periods, the period of active rest, in which recovery is restored, as an introduction to a future preparation period.(13:83)

A proper planning for the transition period allows athletes not only to completely recover after the previous course, but also to get ready for the next preparation period in a good manner, which is better than that of the previous year $(8: 127)$.

\section{CONDITIONS OF TRAINING IN TRANSITION PERIOD}

- Using various training loads.

- Duration of a transition period should range from 3 to 6 weeks.

- Training during a transition period should not contain high volumes of work.

- Training during a transition period should not contain highly effective loads.

\footnotetext{
${ }^{1}$ A lecturer at Department of competitive and aquatic sports in the faculty of physical education - University of Al-Sadat City.
} 
- Volume of work during a transition period should be up to a quarter or one third of work of preparation period.

- Training units per a week should range from 4 to 6 units per week.

- Work trend should be different, various training methods and general exercises should be used.

- Using small games and inactive physical exercises (8:227), (5:124-126).

\section{STAGES OF TRANSITION PERIOD}

First stage: is almost considered a negative rest stage, during which players will be completely far from main training center. They may do many free exercises. Free exercises in direction of flexibility are preferred at any place and any time, without any restrictions.

Second stage: aims to break sporting level. This stage is considered the start of regular training. It contains restrictive exercises of flexibility, small games and inactive exercises which are far from kinetic tracks within original activity, in addition to exercises of the previous period.

Third stage: contains all exercises used during previous periods, in addition to exercises considered an introduction to preparation period such as: general endurance, power endurance and harmony $(8: 127,128)$.

\section{It is called "Stage of temporary loss of sporting level".}

It aims at active rest, so as to get rid of tiredness, restore power constituents, recover from muscle injuries and doing a power-training exercise which equilibrates between static muscle work \& dynamic muscle work and concentrates on general muscles and facing ones (27:294).

Musaad Mahmoud (1997) says that a transition period is a link between competition period and preparation period. In this period, intensity of training should be reduced so as to maintain levels of development acquired through full preparation throughout the previous training season. A continuous training within this period maintains a stable weight. It ranges from 3 to 6 weeks (24:201).

The main purpose of training process is to maintain a player's level and to get it upgraded during the next seasons, according to his physical, skill and mental abilities. Through practical experience, the researcher found that coaches do not pay a good attention to transition periods; however, its purpose is an active rest after season of competitions.

Abull-Ella Abdel-Fattah (1995) indicates that in case a player stops training, he will start to lose anaerobic endurance he has gained (6:227).

If a player loses his fitness during transition period, it will be difficult to get it restored in a short time. Accordingly, a player becomes unable to start a new training course in a high level. Therefore, the transition period is the most suitable one to complete an annual training plan and to prepare to the next one (27:295).

If a player does not make use of the transition period, he will be subjected to dangers of fatigue and boredom in the future, because of the overload. If a player stops training during this period, he will lose power within a week or two weeks. If this power loss continues, it will negatively affect performance. In case a player stops training for a month, he will start to lose aerobic and anaerobic endurance leading to level reduction. Losing these elements makes them difficult to be restored within a 
short time. Accordingly, a player becomes unable to start a new training course in a high level (6:61)(15:83)(27:295).

Ihab Al-Bedewy (2004) states that various methods of training are considered just applied exercises aiming at achieving goal of training process. Methods of training have varied through the transition period. A coach should be aware of these methods in addition to modern ones. Exercises of weights, power, endurance, flexibility and many team games such as basketball, volleyball and football have been done during this period. New methods of training have been introduced during the transition period, as they are vital to using cross training (17).

Mohammed Bereikie and Ihab Al-Bedewy (2004) states that cross training programs within a transition period of a season help players to maintain power and aerobic endurance, through doing many exercises such as running, rope jumping, weights and variable resistances (21:9).

Given that competition of wrestling depends on rating of wrestlers according to their weights, weight adjusting is a problem frequently facing administrators of wrestling. A wrestler is not allowed to participate in a competition, if his weight exceeds the legal one.

Cross training helps all sporting levels to maintain weight and maximum level of fitness. It helps to add variation to action, resulting in amusement. Therefore, traditional exercises can be used such as running, swimming, exercising using different equipment and skiing. It helps to distribute loads of training on different parts of the body, and thus reducing danger of injuries. It also helps to continue training during periods of injuries as one can use different muscles and joints, if a certain part has an injury (33)(34)(35).

Khaled El-Sayed Soroor and Mohammed Ibraheem Gadel-Haq (2008) see that using cross training with its different activities characterized by passion and amusement leads to reducing losses in physical fitness during the transition period(20).

Research problem is summarized in that through researcher's practice of wrestling, he found that in the beginning of preparation season (preparation period), players suffer from a clear reduction of level of physical fitness and an excessive weight in comparison to their level at the end of competition period. This goes back to training stoppage, and letting players without a training program during this period, resulting in a sharp reduction of physical level and an excessive weight due to the negative rest given to players during that period. Thus, importance of transition period is declared as an important period of a training plan, to which coaches and players have not paid an attention, affecting limits of developing physical and technical levels, and contradicting principles of sports training. Researcher has paid an attention to this matter, and he has designed a training program using cross method of training including various activities specialized by passion and amusement, so as to maintain fitness level and body weight, and to reduce their losses. Therefore, players can start a preparation period in a decent and high level in comparison to their start in the previous season.

\section{OBJECTIVES OF RESEARCH}


This research aims to maintain physical level and body weight of a junior wrestler during transition period through:

1. Designing a program using cross method of training during a transition period.

2. Recognizing effects of proposed training program on physical variables being studied and body weight during transition period.

\section{RESEARCH HYPOTHESES}

1. There are statistically insignificant differences between premeasures and postmeasures of experimental group in physical variables being studied and body weight in direction of premeasure.

2. There are statistically significant differences between premeasures and postmeasures of control group in physical variables being studied and body weight in direction of premeasure.

3. There are statistically significant differences between both premeasures of experimental and control groups in physical variables being studied in direction of experimental group.

\section{RESEARCH DEFINITIONS}

Cross training: uses a sport, an activity or any other training technique other that original sport or activity of a player, so as to help to improve performance of original sport or activity $(32: 13)(21: 4)$.

\section{RESEARCH PROCEDURE}

\section{METHOD}

Researcher has used experimental method as it is suitable to the nature of his research. He has used experimental design with premeasures and post measures on two groups (experimental and control).

\section{RESEARCH SAMPLE}

Research sample has been intentionally selected from players of Al Menofeya governorate (first stage) U15, season (2013) who are registered in Egyptian Wrestling Federation. Total number of players has been (30), and we have selected (10) wrestler to do exploratory studies. Thus, the basic study has been applied on (20) wrestlers, divided into two equivalent groups, an experimental group in addition to a control one, 10 wrestler for each. Table (1) shows homogeneity of research sample in variables of growth, fitness and weight.

TABLE (1)

Homogeneity of research sample in physical variables, weight, mass of fats and growth. $(\mathbf{n}=\mathbf{3 0})$

\begin{tabular}{|c|c|c|c|c|c|c|}
\hline \multicolumn{2}{|c|}{$\begin{array}{c}\text { Variables } \\
\end{array}$} & Unit & Mean & $\begin{array}{l}\text { St.Div } \\
\end{array}$ & Median & Skewness \\
\hline \multicolumn{2}{|r|}{ Age } & Year & 13.4 & 1.303 & 13 & -0.217 \\
\hline \multicolumn{2}{|r|}{ Length } & $\mathrm{Cm}$ & 148.633 & 9.568 & 146 & 0.387 \\
\hline \multicolumn{2}{|r|}{ Training age } & Year & 3.2 & 0.997 & 3 & 0.466 \\
\hline \multicolumn{2}{|r|}{ Weight } & $\mathrm{Kg}$ & 43.413 & 9.132 & 41.15 & 0.493 \\
\hline \multicolumn{2}{|r|}{ Fat mass } & $\mathrm{Kg}$ & 5.34 & 1.22 & 5.5 & -0.85 \\
\hline \multirow{2}{*}{\multicolumn{2}{|c|}{$\begin{array}{c}\text { Fast power } \\
\text { Speed of dynamic reaction }\end{array}$}} & Sec & 8.277 & 0.498 & 8.4 & 0.03 \\
\hline & & $\mathrm{Sec}$ & 1.603 & 0.078 & 1.6 & 0.261 \\
\hline \multirow{2}{*}{ 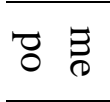 } & Power of right fist & $\mathrm{Kg}$ & 59.733 & 1.874 & 60 & -0.19 \\
\hline & Power of left fist & $\mathrm{Kg}$ & 55.9 & 3.199 & 57 & -0.878 \\
\hline
\end{tabular}




\begin{tabular}{c|c|c|c|c|c|c}
\hline & Power of leg-muscles & $\mathrm{Kg}$ & 95.7 & 10.59 & 91.5 & 1.462 \\
\cline { 2 - 6 } & Power of back-muscles & $\mathrm{Kg}$ & 52.433 & 8.203 & 53 & 0.218 \\
\hline Agility & $\mathrm{Sec}$ & 15.213 & 0.885 & 15.55 & -0.437 \\
\hline Horizontal flexibility & $\mathrm{Cm}$ & 29.167 & 1.704 & 29 & 0.081 \\
\hline Vertical flexibility & $\mathrm{Cm}$ & 35.233 & 1.888 & 35 & 0.232 \\
\hline Power endurance & $\mathrm{Reps}$ & 13.9 & 1.668 & 14 & -0.452 \\
\hline Speed endurance & Reps & 7.4 & 0.932 & 7.5 & -0.099 \\
\hline \hline
\end{tabular}

Table (1) shows that coefficient of torsion of growth and physical variables ranges from (-3) to (3), reflecting homogeneity of research sample in these variables.

\section{EQUIVALENCE OF BOTH RESEACH GROUPS}

\section{TABLE (2)}

SMA \& Standard Deviation, value of " $T$ " and its indications related to physical variables, weight, mass of fats and growth for both groups (Experimental / Control). $(\mathbf{N} 1=$ N2 = 10)

\begin{tabular}{|c|c|c|c|c|c|c|c|}
\hline \multirow{2}{*}{\multicolumn{2}{|c|}{ Variables }} & \multirow[t]{2}{*}{ Unit } & \multicolumn{2}{|c|}{$\begin{array}{l}\text { Experimental } \\
\text { Group }(n=10)\end{array}$} & \multicolumn{2}{|c|}{$\begin{array}{c}\text { Control Group } \\
(\mathrm{n}=10)\end{array}$} & \multirow[t]{2}{*}{$\mathbf{T}$} \\
\hline & & & Mean & St.Div & Mean & St.Div & \\
\hline & Age & year & 13.6 & 1.429 & 13.1 & 1.287 & 0.822 \\
\hline & Length & $\mathrm{cm}$ & 150.3 & 9.911 & 147.6 & 10.394 & 0.594 \\
\hline & Training age & year & 3.2 & 1.135 & 3 & 0.817 & 0.452 \\
\hline & Weight & $\mathrm{kg}$ & 44.08 & 10.143 & 44.01 & 8.891 & 0.016 \\
\hline & Fat mass & $\mathrm{kg}$ & 5.38 & 1.365 & 5.34 & 1.196 & 0.07 \\
\hline & Fast power & sec & 8.42 & 0.492 & 8.17 & 0.512 & 1.113 \\
\hline \multicolumn{2}{|c|}{ Speed of dynamic reaction } & sec & 1.628 & 0.065 & 0.608 & 0.079 & 0.614 \\
\hline \multirow{4}{*}{ 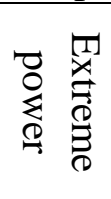 } & Power of right fist & $\mathrm{kg}$ & 60 & 1.155 & 59.4 & 0.802 & 0.802 \\
\hline & Power of left fist & $\mathrm{kg}$ & 55 & 3.621 & 56.5 & 1.09 & 1.09 \\
\hline & Power of leg-muscles & $\mathrm{kg}$ & 97 & 11.547 & 96.5 & 12.634 & 0.092 \\
\hline & Power of back-muscles & $\mathrm{kg}$ & 52.6 & 7.245 & 50.4 & 0.618 & 0.618 \\
\hline & Agility & $\mathrm{sec}$ & 15.17 & 0.957 & 15.56 & 0.756 & 1.011 \\
\hline \multicolumn{2}{|r|}{ Horizontal flexibility } & $\mathrm{cm}$ & 29.1 & 1.792 & 29.3 & 1.829 & 0.247 \\
\hline \multicolumn{2}{|r|}{ Vertical flexibility } & $\mathrm{cm}$ & 34.3 & 1.567 & 35.6 & 1.429 & 1.938 \\
\hline \multicolumn{2}{|r|}{ Power endurance } & Reps & 13.7 & 1.767 & 13.4 & 1.349 & 0.427 \\
\hline \multicolumn{2}{|r|}{ Speed endurance } & Reps & 7.3 & 0.823 & 7 & 0.817 & 0.818 \\
\hline
\end{tabular}

Table value of " $T$ " at level $(0.05)=(2.101)$

Table (2) shows that there have been statically insignificant differences between both groups (Experimental/Control) in growth and physical variables being studied. This indicates that both groups are equivalent in these variables, where calculated value of "T" is less than its table value.

\section{TOOLS \& EQUIPMENT USED TO COLLECT DATA}

\section{REFERENCE SURVEY}

Researcher has surveyed scientific references and studies involved cross training during transition period, which is the topic being studied, within available limitations; aiming to know methods and physical content of cross training program, in addition to make use of these references in preparing programs and formulating loads. He also aims to make use of their results in discussing results of this study.

2. FORM OF QUESTIONNAIRE - (attachment No. 2). 
Researcher has made questionnaire, so as to explore opinions of experts (attachment No. 1) in the field of study-variables through communication and personal meetings aiming to express opinions towards program variables, training sets, determining elements of physical fitness and its relative importance during transition period in addition to appropriate exercises for it to be measured. This has been done in the period ranging from 09/02/2013 AD to 06/03/2013 AD. Addition and deleting have been taken into account in accordance with opinion of experts.

\section{TESTS USED IN RESEARCH - (attachment No. 4).}

Test of fast power for wrestlers - test of fitness for wrestlers - test of dynamic response for wrestlers - test of extreme power for wrestlers (test of power for both right and left fists - test of power for muscles of legs and back) - flexibility test (horizontal and vertical distances of bridge) - test of power endurance for wrestlers test of speed endurance for wrestlers - body-composition analyzer.

\section{DEVICES \& EQUIPMENT USED IN RESEARCH}

Electronic scale to measure weight to the nearest kilogram - restameter to measure lengths to the nearest centimeter - a ruler to measure flexibility - stop watch to measure time to the nearest 0.01 second - polar watch - Manometer to measure power of fist - Dynamometer to measure power of muscles of legs and back Kinetic velocity measuring device (video camera - a computer - Animation shop 3) Wrestling carpet - wrestling pillars of different weights - graded-resistance rubbers a shallow pool - graded-medical balls - jumping ropes - low-rise strips - climbing net - climbing ropes.

\section{DATA FORM (attachment No. 3).}

\section{Proposed training program of experimental group (attachment No. 5).}

\section{Training program has been prepared using the following procedure:}

- Researcher has surveyed Arabic and foreign references within limits of his knowledge.

- A survey has been made for researches and studies related to variables of research in the field of cross training during transition period of wrestling and other sports. Most previous studies and references have used matrix of cross training activities, which is considered to be exercises done using expensive modern devices which aren't available in most clubs, unless a few number of devices is available, such as (rowing - climbing arm argometer - static bike - moving chain ...). Most of these devices are not suitable for ages used in this research, so researcher has used some alternative devices, within available limits, which achieve goals of program, fit to cross-method content, safe and are suitable for ages used herein.

- Meeting and contacting the experts in wrestling.

\section{MAIN OBJECTIVE OF PROGRAM}

Program aims at:

1. Maintaining fitness level of a junior wrestler during transition period.

2. Maintaining weight of a junior wrestler during transition period.

\section{PRINCIPLES OF PROGRAM}

a. Building the program according to scientific principles.

b. Training program should fit to stated objectives. 
c. Training program and its constituents should fit to selected ages of sample and cross-training method used herein.

d. It should be elastic and able to be amended.

e. Making use of previous studies which have designed training programs using cross method.

f. Continuity and regularity in implementing training program so as to result in the desired benefit.

g. Taking into account principles of training while writing down a training program for training units such as (warm up - main part - end).

h. Taking into account individual differences while preparing a program.

i. Training doses should be without overloads in comparison to loads implemented during season.

j. Load level should be raised gradually until the end of transition period and the start of preparation period.

k. Load intensity should be low and moderate.

1. Activity content should be different from original activity as possible.

m. Training environment should be different from original activity's one, otherwise, dynamic activity should be different.

n. Training should be characterized by fun and passion as possible.

o. Content of dynamic activity should be small games as possible.

\section{DETERMINANTS OF TRAINING PROGRAM}

Program application period:

Program will have been implemented during transition period, and its duration has been determined to be (6) weeks,(4) training units for each.

- Number of units of general program is (24) units.

- Duration of a unit have ranged gradually from (60) to (90) minutes through transition period.

- Total duration of program is (1800) minutes or (30) hours.

TABLE (3)

Distribution of total volume of program

\begin{tabular}{c|c|c|c|c|c|c}
\hline \hline Week & No. of units & $\begin{array}{c}\text { Unit duration } \\
(\text { minutes })\end{array}$ & $\begin{array}{c}\text { Weekly period } \\
(\text { minutes })\end{array}$ & $\begin{array}{c}\text { Load intensity } \\
(\%)\end{array}$ & $\begin{array}{c}\text { Pulse rate } \\
(\mathbf{p} / \mathbf{m})\end{array}$ & $\begin{array}{c}\text { Work to } \\
\text { rest ratio }\end{array}$ \\
\hline \hline $1^{\text {st }}$ & 4 & 60 & 240 & $50 \%$ & 141 & $1: 3$ \\
\hline $2^{\text {nd }}$ & 4 & 60 & 240 & $55 \%$ & 147 & $1: 3$ \\
\hline $3^{\text {rd }}$ & 4 & 75 & 300 & $60 \%$ & 154 & $1: 3$ \\
\hline $4^{\text {th }}$ & 4 & 75 & 300 & $55 \%$ & 146 & $1: 3$ \\
\hline $5^{\text {th }}$ & 4 & 90 & 360 & $65 \%$ & 160 & $1: 3$ \\
\hline $6^{\text {th }}$ & 4 & 90 & 360 & $67 \%$ & 163 & $1: 3$ \\
\hline TOTAL & 24 & & 1800 & & & \\
\hline \hline
\end{tabular}

Training methods used herein:

(Low intensity periodic training - circular training - continuous training)

Formulating training load. (Attachment no. 5):

Researcher has used wavy method to formulate load during periods of program, where he has used:

- Formula $(1-3)$ and $(1-2)$. 


\section{Determining intensity of training loads:}

Intensity of training loads used in this program has been determined, where high intensity has reached $(75-84 \%)$, moderate intensity $(65-74 \%)$ and low intensity $(50-64 \%)$.

\section{Regularization of training-load intensities:}

Training load intensity has been regularized using pulse rate and applying the following equation:

- Target Heart Rate $(\mathrm{THR})=$ rest pulse $+($ training ratio $\times($ maximum pulse - rest pulse)), where:

- Average age of sample $=13$ years.

- Average rest-pulse rate of sample $=74 \mathrm{p} / \mathrm{m}$.

- Maximum pulse of sample $=220-$ age $=220-13=207 \mathrm{p} / \mathrm{m}$.

- Margin pulse of sample $=$ maximum pulse rate - rest pulse rate $=207-74=133$ $\mathrm{p} / \mathrm{m}$.

- Determination of training-pulse rate $=($ margin pulse $\times$ target intensity $)+$ Rest pulse. (4: 235).

\section{Regularizing training loads using pulse rate:}

$\begin{array}{llll}\text { High load } & \text { Ratio }(75: 84 \%) & \text { Its rate of pulse is: } & (174: 186 \mathrm{p} / \mathrm{m}) \text {. } \\ \text { Moderate load } & \text { Ratio }(65: 74 \%) & \text { Its rate of pulse is: } & (160: 172 \mathrm{p} / \mathrm{m}) \text {. } \\ \text { Low load } & \text { Ratio }(50: 64 \%) & \text { Its rate of pulse is: } & (141: 159 \mathrm{p} / \mathrm{m}) \text {. }\end{array}$

TABLE (4)

Principles of formulating training load depending on duration of implementing, according to power-producing systems

\begin{tabular}{|c|c|c|c|c|c|}
\hline Power system & $\begin{array}{c}\begin{array}{c}\text { Duration of exercise } \\
\text { (work) }\end{array} \\
\end{array}$ & $\begin{array}{c}\text { Number of times } \\
\text { of an exercise. }\end{array}$ & No. of groups & $\begin{array}{c}\begin{array}{l}\text { Work to rest } \\
\text { ratio }\end{array} \\
\end{array}$ & Type of rest \\
\hline $\begin{array}{l}\text { Phosphate } \\
\text { system } \\
\text { ATP - PC }\end{array}$ & $\begin{array}{l}10 \mathrm{sec} . \\
15 \mathrm{sec} . \\
20 \mathrm{sec} . \\
25 \mathrm{sec} .\end{array}$ & $\begin{array}{c}10 \\
9 \\
10 \\
8 \\
\end{array}$ & $\begin{array}{l}5 \\
5 \\
4 \\
4\end{array}$ & $1: 3$ & $\begin{array}{l}\text { Active rest } \\
\text { (walking - } \\
\text { stretches) }\end{array}$ \\
\hline $\begin{array}{c}\text { Phosphate and } \\
\text { lactic system } \\
\text { ATP - PC, } \\
\text { LA }\end{array}$ & $\begin{array}{c}30 \mathrm{sec} . \\
40-50 \mathrm{sec} . \\
60-70 \mathrm{sec} . \\
80 \mathrm{sec} .\end{array}$ & $\begin{array}{l}5 \\
5 \\
5 \\
5 \\
\end{array}$ & $\begin{array}{l}5 \\
4 \\
3 \\
3\end{array}$ & $1: 3$ & $\begin{array}{c}\text { Light to } \\
\text { moderate } \\
\text { work of trot. }\end{array}$ \\
\hline $\begin{array}{l}\text { Lactic and } \\
\text { Oxygen } \\
\text { system } \\
\text { LA - O2 }\end{array}$ & $\begin{array}{c}1.3-2 \mathrm{~min} . \\
2.2-2.4 \mathrm{~min} \\
2.5-3 \mathrm{~min}\end{array}$ & $\begin{array}{l}4 \\
6 \\
4\end{array}$ & $\begin{array}{l}2 \\
1 \\
1\end{array}$ & $\begin{array}{l}2: 1 \\
1: 1\end{array}$ & $\begin{array}{l}\text { Light to } \\
\text { moderate } \\
\text { exercises. }\end{array}$ \\
\hline $\begin{array}{l}\text { Oxygen } \\
\text { system. } \\
\mathrm{O} 2 \\
\end{array}$ & $\begin{array}{l}3-4 \min . \\
4-5 \min .\end{array}$ & $\begin{array}{l}3 \\
4\end{array}$ & $\begin{array}{l}1 \\
1\end{array}$ & $\begin{array}{l}1: 1 \\
1: 2\end{array}$ & $\begin{array}{c}\text { Exercises or } \\
\text { rest. }\end{array}$ \\
\hline
\end{tabular}

$(8: 282)(107: 91)$

\section{PARTS OF TRAINING UNIT OF EXPERIMENTAL GROUP}

Training unit is consisted of the following parts as well (warming up by $15 \%$, the main part by $80 \%$ then the end by $5 \%$ ).

\section{Warming up:}


This part of training unit mainly aims to prepare a player from all aspects for the main part of work, work for giving muscles required flexibility and elasticity, raise body's temperature, prepare to dynamic work of unit and try to reach the maximum reacting ability.

\section{The main part:}

This part of unit contains variable exercises which differ from wrestling skills and matches as possible, and are characterized by passion and amusement, such as competitive small games, double training by body weight (lifting, pull and push), rope climbing, climbing net, rope jumping, swimming exercises, water games, general flexibility exercises, power exercises using rubber, Belometric training on strips, Gymnastics (ground device, parallel device, horizontal bar, ring device and American football), football, basketball and long-distance running, with flexibility in applying game rules.

3. The end:

This part of training unit aims to get a player back to his normal status or to a close one as possible, after exertion. In this part relaxation exercises are used in which load is reduced.

\section{Control group has used negative rest (no kinetic action), they have not had any systematic food program.}

\section{PROPOSED FOOD PROGRAM FOR EXPERIMENTAL GROUP. (Attachment No.6)}

\section{Special variables to maintain weight:}

- Emphasis on players not to eat any food between main meals.

- Emphasis on players to be committed to ingredients of meals.

- Food program is applied at times of main meals. Breakfast is at 9:00 AM, then a light meal in-betweens. Lunch is at 3:00 PM, then a light meal after training. Dinner is at 9:00 Pm.

- Sporting program is applied in its time, 3 hours after lunch, i.e. at 6:00 PM.

- Dinner should be 3 - 4 hours before sleep time, to allow digestion.

- Emphasis on players and their parents to try to maintain weight and physical level, by committing to follow instructions of food program and sports program.

- Body weight should be measured daily while applying sports and food program.

- Actual calories should be daily calculated using relevant daily report.

GENERAL CONDITIONS OF A BALANCED COMPLETE MEAL

- A balanced complete food program should be followed, taking into account type and amount of food eaten by a player in accordance with requirements of training or competition.

- Taking into account volume of physical exertion in training and competition, in accordance with scientific principles of training and game rules.

- Taking into account ages (juniors, youth and seniors), as well as gender (males and females). 
- Applying principle of tasting in food programs without prejudice to food balance.

- Food should include big amounts of mineral salts and vitamins to maintain chemical balance of a body.

- Animal sources such as meats and birds, which do not contain fats because of basic Amino acids resulting in a good psychological and physical equilibrium for a player.

- Adding salt and yolk so as to maximize food value.

- Salad and lemon juice providing body with vitamin C.

- Adding vegetable oil such as corn oil and sun flower oil so as to provide body with vitamins solved in fats.

- One or two pills of mature, crunchy or fresh fruits containing vitamin $\mathrm{C}$ which is vital to muscular contraction and resisting fatigue and cold, in addition to Potassium that leaves an alkaline residue that allows a body to resist acidity resulting from muscular fatigue.

- Butter or cream containing vitamins $\mathrm{D}$ and $\mathrm{A}$, in addition to taking into account ratio of fats in cold weather.

- Milk is rich in Amino acids.

- Jam, honey or fruit cakes to provide body with Fructose.

- Simit or toasts containing aliphatic acid which is easily absorbed.

- Rice or boiled potatoes to achieve a good concentration of glucose in blood before competition and storing glycogen in liver in a sufficient and fast amount.

- An appropriate amount of salt should be added to a meal to achieve a good sodium chloride store, taking into account increasing this amount in hot weather.

A meal should be easy to digest, and to achieve this, one should take into account:

- Prescribed ratios of basic ingredients of meals.

- Eating easily-digested vegetables such as beans, peas, potatoes, carrots and salad.

- Avoiding legumes as it slows down process of digestion.

- Avoiding iced food and soda water.

- Eating boiled fishes.

- Avoiding foods with ketchups cooked using fats as it results in indigestion.

- Avoiding drinking big amounts of water directly before, during or after eating, as this leads to reduction in concentrations of digestive juices in stomach and delaying digestion accordingly.

- A boy's need for water depends on many factors; the most important ones are (age, environmental conditions, volume of activity, type \& amount of food and bioprocesses).

TABLE (5)

A human's daily balance between water intake and loss.

\begin{tabular}{c|c|c|c}
\hline \hline \multicolumn{2}{c|}{ Water intake } & \multicolumn{2}{c}{ Water loss } \\
\hline Type & $\begin{array}{c}\text { Amount } \\
\text { (Milliliters) }\end{array}$ & Type & $\begin{array}{c}\text { Amount } \\
\text { (Milliliters) }\end{array}$ \\
\hline \hline Drinking water and other liquids. & 1000 & Urine and feces water. & 1200 \\
\hline Water in food. & 700 & Foreseen and unforeseen perspiration & 600 \\
\hline
\end{tabular}


Water of metabolism. TOTAL

300

2000
Water in exhaled air

TOTAL
200

2000

Table (5) shows that a player's need to water interferes in the amount of eaten food in addition to other liquids, and he loses water by different means of expulsion. Therefore, a player's weight is not affected by amount of water he intakes, as long as he intakes water in accordance to his daily needs only. (26:26) (5:25) (13:34) (23:152) (30:29) (19:261) (28:282).

TABLE (6)

An amount of a meal, and its daily ingredients giving body required calories

\begin{tabular}{c|c|c|c|c|c|c|c}
\hline \hline \multirow{2}{*}{$\begin{array}{c}\text { Mmount of a meal, } \\
\text { and its daily } \\
\text { ingredients. }\end{array}$} & \multicolumn{3}{|c|}{ Meals } & \multicolumn{3}{c|}{ Ingredients per meal } & \multirow{2}{*}{ TOTAL } \\
\cline { 2 - 8 } & Breakfast & Lunch & Dinner & Protein & Carbohydrates & Fats & \\
\hline Food quantity & $35 \%$ & $40 \%$ & $25 \%$ & $10 \%$ & $65 \%$ & $25 \%$ & $100 \%$ \\
\hline \hline
\end{tabular}

$(19: 212)$

TABLE (7)

Body daily needs of energy for various muscle works.

\begin{tabular}{c|c}
\hline \hline Work type & Body daily needs of calories (C) \\
\hline \hline A work requiring moderate physical exertion. & $2000-2400$ \\
\hline A work requiring above-average physical exertion. & $2400-2800$ \\
\hline A work requiring less maximum physical exertion. & $2800-3300$ \\
\hline A work requiring violent physical exertion. & $3300-4000$ and more \\
\hline \hline
\end{tabular}

$(19: 162)$

Table (7) shows body needs of energy to do any physical work. We find that calories required for a certain physical exertion vary in accordance with load intensity.

How to calculate body needs of calories, carbohydrates, proteins and fats?

$\mathbf{1}^{\text {st }}$ Step:

Calculating basic metabolic rate using Mifflin method.

BMR $($ Basal metabolic rate for men $)=(9.99 \times$ weight $(\mathrm{kg}))+.(6.25 \times$ length $(\mathrm{cm}))-$ $(4.92 \times$ age $)+5$

$2^{\text {nd }}$ Step:

To know coefficient of activity required by activity being exercised.

TABLE (8)

Rate of activity required by activity being exercised.

\begin{tabular}{c|c}
\hline \hline Type of activity & Rate of activity \\
\hline \hline In case of sedentary (sitting, study, printing or writing) & $1.2 \%$ \\
\hline In case of light activity (walking for less than 2 hours per day) & $1.375 \%$ \\
\hline In case of moderate activity (house work, dancing and playing sports for (3-5) days per week). & $1.55 \%$ \\
\hline In case of extreme activity (playing sports for (5 - 6) days per week. & $1.725 \%$ \\
\hline In case of very extreme activity (physical work or sports training). & 1.9 or 2.00\% \\
\hline \hline
\end{tabular}

$3^{\text {rd }}$ Step:

Calculating total energy:

Where total energy $=$ metabolic rate $\times$ coefficient of activity.

$4^{\text {th }}$ Step:

- Calculating amount of proteins: 
- Needs of males reaches 1.3 up to 1.6 grams $/ \mathrm{kg} /$ day.

- Quantity in grams = weight (in kg.) $\times 1.3$

- We multiply quantity (in grams) $\times 4.1$ which is number of calories per gram of protein, so as to get the quantity needed by an individual in calories.

$5^{\text {th }}$ Step:

- Calculating quantity of fats, where an individual needs to $25 \%-30 \%$ of fats.

- Quantity (in calories) = total energy $\times(25 / 100)$.

- Required quantity (in grams) = Quantity (in calories /9)

$6^{\text {th }}$ Step:

Calculating quantity of carbohydrates.

- Required quantity of carbohydrates $=($ calories of proteins + calories of fats $)-$ total energy.

- Required quantity of carbohydrates (in grams) = quantity (in calories) / 4.1

$(11: 197)(20: 15)$

Contains chemical composition of many types of food, and the ability of its constituents to generate calories. It also contain an example for meals over one day for an individual of search sample (36). Attachment No.(6)

- Surveys

Researcher has selected a random sample of 10 players from society of research, outside original sample of research. He has tested them with the help of his assistants on 13/3/2013 AD : 15/3/2013 AD.

\section{Objective of this study:}

- Making sure that measures and tests have been done correctly, and that devices \& tools and its relevant procedure have been valid in accordance with its prescribed terms and suitability of place.

- Identifying time required for measuring process, and the time elapsed by each player for each test.

- Identifying probable errors during implementing measures and tests, arranging their course and knowing the extent to which they are suitable for ages herein.

We have made sure of suitability of tests for research sample, as well as tools and place where measures have been done. In addition, we have ensured that assistants are familiar with how tests are done, so as to avoid measuring errors.

\section{SCIENTIFIC COEFFICIENTS FOR USED TESTS}

\section{Test validity:}

Researcher has calculated distinction validity between two groups, one of them is indistinctive, from the outside of original research sample, and the other is distinctive (the exploratory) from 13 to 15 / 3 / 2013. Each group has contained (10) wrestlers.

\section{TABLE (9)}

Indications of differences between both groups (distinctive and indistinctive), within physical tests being researched. $(\mathrm{N} 1=\mathrm{N} 2=10)$.

\begin{tabular}{c|c|c|c|c|c|c}
\hline \hline \multirow{2}{*}{ Variables } & \multirow{2}{*}{ Unit } & \multicolumn{2}{|c|}{ Distinctive group } & \multicolumn{2}{|c|}{ In distinctive group } & \multirow{2}{*}{ T } \\
\cline { 3 - 6 } & & Mean & St.Div & Mean & St.Div & \\
\hline \hline Fast power & sec & 8.24 & 0.508 & 9.98 & 0.709 & $6.302^{*}$ \\
\hline \hline
\end{tabular}




\begin{tabular}{|c|c|c|c|c|c|c|c|}
\hline \multicolumn{2}{|c|}{ Speed of dynamic reaction } & $\mathrm{sec}$ & 1.572 & 0.048 & 1.824 & 0.066 & $7.442 *$ \\
\hline \multirow{4}{*}{ 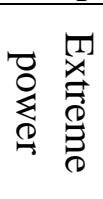 } & Power of right fist & $\mathrm{kg}$ & 59.8 & 2.348 & 54.7 & 2.983 & $4.248^{*}$ \\
\hline & Power of left fist & $\mathrm{kg}$ & 56.2 & 3.553 & 52.9 & 2.726 & $2.33 *$ \\
\hline & Power of leg-muscles & $\mathrm{kg}$ & 93.6 & 7.806 & 83 & 2.404 & $4.104^{*}$ \\
\hline & Power of back-muscles & $\mathrm{kg}$ & 54.3 & 9.031 & 45 & 2.789 & $3.111^{*}$ \\
\hline & Agility & sec & 14.91 & 0.893 & 16.63 & 0.419 & $5.516^{*}$ \\
\hline & Iorizontal flexibility & $\mathrm{cm}$ & 29.1 & 1.663 & 34.4 & 1.265 & $8.02 *$ \\
\hline & Vertical flexibility & $\mathrm{cm}$ & 30.8 & 2.348 & 31.7 & 1.883 & $4.303 *$ \\
\hline & Power endurance & Reps & 14.6 & 1.776 & 11 & 1.054 & $5.511^{*}$ \\
\hline & Speed endurance & Reps & 7.9 & 0.994 & 5.6 & 0.516 & $6.491 *$ \\
\hline
\end{tabular}

Table value of "T" at level $(0.05)=(2.101)$

Table (9) shows that there have been statically insignificant differences for distinctive group. This indicates test validity.

2. Stability of tests:

Researcher has calculated stability of tests by retesting an exploratory sample of 10 wrestlers on 19, 20 / 3 / $2013 \mathrm{AD}$, after a break of one week between the two applications.

TABLE (10)

SMA, standard deviation and coefficient of correlation between $1^{\text {st }}$ and $2^{\text {nd }}$ applications of physical tests being studied for the exploratory sample $(\mathrm{N}=10)$.

\begin{tabular}{|c|c|c|c|c|c|c|c|}
\hline \multirow{2}{*}{\multicolumn{2}{|c|}{ Variables }} & \multirow{2}{*}{ Unit } & \multicolumn{2}{|c|}{$\mathbf{1}^{\text {st }}$ application } & \multicolumn{2}{|c|}{$\overline{2^{\text {nd }}}$ application } & \multirow{2}{*}{$\mathbf{R}$} \\
\hline & & & Mean & St.Div & Mean & St.Div & \\
\hline & Fast power & $\mathrm{sec}$ & 8.24 & 0.508 & 8.16 & 0.458 & $0.983 *$ \\
\hline \multicolumn{2}{|c|}{ Speed of dynamic reaction } & $\mathrm{sec}$ & 1.572 & 0.084 & 1.548 & 0.059 & $0.877^{*}$ \\
\hline \multirow{4}{*}{ 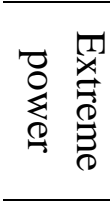 } & Power of right fist & $\mathrm{kg}$ & 59.8 & 2.348 & 60.1 & 2.183 & $0.98^{*}$ \\
\hline & Power of left fist & $\mathrm{kg}$ & 56.2 & 3.553 & 56.7 & 3.057 & $0.988^{*}$ \\
\hline & Power of leg-muscles & $\mathrm{kg}$ & 93.6 & 7.806 & 94.3 & 7.134 & $0.984 *$ \\
\hline & Power of back-muscles & $\mathrm{kg}$ & 54.3 & 9.031 & 54.9 & 8.478 & $0.997 *$ \\
\hline \multicolumn{2}{|r|}{ Agility } & $\mathrm{sec}$ & 14.91 & 0.893 & 14.76 & 0.804 & $0.98^{*}$ \\
\hline \multicolumn{2}{|r|}{ Horizontal flexibility } & $\mathrm{cm}$ & 29.1 & 1.663 & 28.7 & 1.567 & $0.951^{*}$ \\
\hline \multirow{2}{*}{\multicolumn{2}{|c|}{$\begin{array}{l}\text { Vertical flexibility } \\
\text { Power endurance }\end{array}$}} & $\mathrm{cm}$ & 30.8 & 2.348 & 36.1 & 2.234 & $0.979^{*}$ \\
\hline & & Reps & 14.6 & 1.776 & 15 & 1.414 & $0.973 *$ \\
\hline \multicolumn{2}{|r|}{ Speed endurance } & Reps & 7.9 & 0.994 & 8.2 & 0.632 & $0.742 *$ \\
\hline
\end{tabular}

Table value of "R" at level $(0.05)=(0.632)$

Table (10) shows that calculated value of " $R$ " is bigger than its table value. This indicates the stability of tests being studied.

Pre measurements:

Premeasures have been done on 22, 23/3/2013 for members of research sample, where competition has been on 25, 26/3/2013. Then, there has been a negative rest for (3) days. After that, proposed program has been applied.

\section{Program implementation:}

Proposed program has been applied in the period ranging from 30/3/2013 AD to 10/5/2013 AD.

\section{Post-measures:}

Post-measures have been done on 11, 12/5/2013; using the same conditions and specifications of premeasures, and in the same place. 


\section{Statistical processing:}

Researcher has used the following statistical operations in processing data of this study:

- Skewness

-The percentage of improvement

-Median -The standard deviation

-T test -ETA ${ }^{2}$ coefficient
-Arithmetic mean

-Correlation coefficient

\section{Presentation and discussion of the results:}

First: Presentation of the results:

TABLE (11)

Indications of differences between both premeasures and post-measures of experimental group in physical variables, weight and mass of fats. $(N=10)$.

\begin{tabular}{|c|c|c|c|c|c|c|}
\hline \multirow{2}{*}{\multicolumn{2}{|c|}{ Variables }} & \multicolumn{2}{|c|}{ Premeasure } & \multicolumn{2}{|c|}{ Post-measure } & \multirow{2}{*}{$\mathbf{T}$} \\
\hline & & Mean & St.Div & Mean & St.Div & \\
\hline & Fast power & 8.42 & 0.492 & 8.422 & 0.493 & 1.5 \\
\hline \multicolumn{2}{|c|}{ Speed of dynamic reaction } & 1.628 & 0.065 & 1.644 & 0.061 & 1.809 \\
\hline \multirow{4}{*}{ 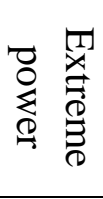 } & Power of right fist & 60 & 1.155 & 59.8 & 1.476 & 1.5 \\
\hline & Power of left fist & 55 & 3.621 & 54 & 3.33 & 1.088 \\
\hline & Power of leg-muscles & 97 & 11.547 & 96.8 & 11.669 & 1.5 \\
\hline & Power of back-muscles & 52.6 & 7.245 & 52.5 & 7.307 & 1 \\
\hline \multicolumn{2}{|r|}{ Agility } & 15.17 & 0.957 & 15.185 & 0.952 & 1.567 \\
\hline \multicolumn{2}{|r|}{ Horizontal flexibility } & 29.1 & 1.792 & 27.4 & 0.349 & $7.965^{*}$ \\
\hline \multicolumn{2}{|r|}{ Vertical flexibility } & 34.3 & 1.567 & 35 & 1.491 & $4.583 *$ \\
\hline \multicolumn{2}{|r|}{ Power endurance } & 13.7 & 1.767 & 13 & 1.333 & 1.561 \\
\hline \multicolumn{2}{|r|}{ Speed endurance } & 7.3 & 0.823 & 6.9 & 0.567 & 1.5 \\
\hline \multicolumn{2}{|r|}{ Body weight } & 44.08 & 10.143 & 44.25 & 10.063 & 1.182 \\
\hline \multicolumn{2}{|r|}{ Mass of fats } & 5.38 & 1.365 & 5.46 & 1.294 & 1.177 \\
\hline
\end{tabular}

Table value of "T" at level $(0.05)=(1.833)$

Table (11) shows that there are no statistically significant differences between premeasures and post-measures of experimental group for physical variables being studied, in addition to weight and mass of fats. Where we find that calculated value of " $T$ " is less than its table value for all variables excepting for horizontal and vertical flexibilities, where there are statistical indication, as calculated value of " $T$ " is larger than its table value.

\section{TABLE (12)}

Indications of differences between both premeasures and postmeasures of control group in physical variables, weight and mass of fats. $(\mathbf{N}=\mathbf{1 0})$.

\begin{tabular}{|c|c|c|c|c|c|c|c|}
\hline \multirow{2}{*}{\multicolumn{2}{|c|}{ Variables }} & \multicolumn{2}{|c|}{ Premeasure } & \multicolumn{2}{|c|}{ Post-measure } & \multirow{2}{*}{$\mathbf{T}$} & \multirow{2}{*}{ Direction } \\
\hline & & Mean & St.Div & Mean & St.Div & & \\
\hline & Fast power & 8.17 & 0.512 & 9.6 & 0.516 & $21.423^{*}$ & Premeasure \\
\hline \multicolumn{2}{|c|}{ Speed of dynamic reaction } & 1.608 & 0.079 & 1.804 & 0.102 & $14.08 *$ & Premeasure \\
\hline \multirow{4}{*}{ 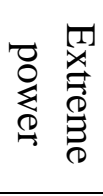 } & Power of right fist & 59.4 & 2.066 & 56.1 & 1.663 & $11^{*}$ & Premeasure \\
\hline & Power of left fist & 56.5 & 2.415 & 49.4 & 3.169 & $9.261 *$ & Premeasure \\
\hline & Power of leg-muscles & 96.5 & 12.634 & 86.9 & 12.538 & $8.515 *$ & Premeasure \\
\hline & Power of back-muscles & 50.4 & 8.618 & 44.5 & 7.122 & $4.892 *$ & Premeasure \\
\hline
\end{tabular}




\begin{tabular}{c|c|c|c|c|c|c}
\hline Agility & 15.56 & 0.756 & 16.6 & 0.699 & $5.461^{*}$ & Premeasure \\
\hline Horizontal flexibility & 29.3 & 1.829 & 31.4 & 1.429 & $3.706^{*}$ & Premeasure \\
\hline Vertical flexibility & 35.6 & 1.429 & 33.3 & 0.675 & $6.866^{*}$ & Premeasure \\
\hline Power endurance & 13.4 & 1.349 & 11.1 & 0.876 & $6.866^{*}$ & Premeasure \\
\hline Speed endurance & 7 & 0.817 & 5.7 & 0.675 & $8.51^{*}$ & Premeasure \\
\hline Body weight & 44.01 & 8.891 & 48 & 8.997 & $31.231^{*}$ & Premeasure \\
\hline Mass of fats & 5.34 & 1.196 & 6.9 & 1.022 & $14.085^{*}$ & Premeasure \\
\hline \hline
\end{tabular}

Table value of "T" at level $(0.05)=(1.833)$

Table (12) shows that there are statistically significant differences between premeasures and post-measures of control group for premeasure of physical variables, weight and mass of fats, where the calculated value of "T" is larger than its table one for all variables.

\section{TABLE (13)}

Indications of differences between premeasures and post-measures of experimental and control groups in physical variables, weight and mass of fats.

$\mathrm{N} 1=\mathrm{N} 2=\mathbf{1 0}$

\begin{tabular}{|c|c|c|c|c|c|c|}
\hline \multirow{2}{*}{\multicolumn{2}{|c|}{ Variables }} & \multicolumn{2}{|c|}{ Experimental } & \multicolumn{2}{|c|}{ Control } & \multirow{2}{*}{$\mathbf{T}$} \\
\hline & & Mean & St.Div & Mean & St.Div & \\
\hline & Fast power & 8.422 & 0.493 & 9.6 & 0.516 & $5.21 *$ \\
\hline \multicolumn{2}{|c|}{ Speed of dynamic reaction } & 1.644 & 0.061 & 1.804 & 0.102 & $4.248^{*}$ \\
\hline \multirow{4}{*}{ 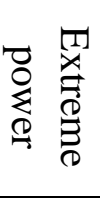 } & Power of right fist & 59.8 & 1.476 & 56.1 & 1.663 & $5.262 *$ \\
\hline & Power of left fist & 54 & 3.33 & 49.4 & 3.169 & $3.163 *$ \\
\hline & Power of leg-muscles & 96.8 & 11.669 & 86.9 & 12.538 & $1.828 *$ \\
\hline & Power of back-muscles & 52.5 & 7.307 & 44.5 & 7.122 & $2.479 *$ \\
\hline \multirow{2}{*}{\multicolumn{2}{|c|}{$\begin{array}{c}\text { Agility } \\
\text { Horizontal flexibility }\end{array}$}} & 15.185 & 0.956 & 16.6 & 0.699 & $3.778 *$ \\
\hline \multirow{2}{*}{\multicolumn{2}{|c|}{$\begin{array}{l}\text { Horizontal flexibility } \\
\text { Vertical flexibility }\end{array}$}} & 27.4 & 0.349 & 31.4 & 1.429 & $6.433 *$ \\
\hline & & 35 & 1.491 & 33.3 & 0.675 & $3.285^{*}$ \\
\hline \multicolumn{2}{|r|}{ Power endurance } & 13 & 1.333 & 11.1 & 0.876 & $3.767 *$ \\
\hline \multicolumn{2}{|r|}{ Speed endurance } & 6.9 & 0.567 & 5.7 & 0.675 & $4.303^{*}$ \\
\hline \multicolumn{2}{|r|}{ Body weight } & 44.25 & 10.063 & 48 & 8.997 & 0.879 \\
\hline \multicolumn{2}{|r|}{ Mass of fats } & 5.46 & 1.294 & 6.9 & 1.022 & $3.028 *$ \\
\hline
\end{tabular}

Table value of "T" at level $(0.05)=(1.743)$

Table (13) shows that there have been statistically significant differences between both premeasures of experimental and control groups, in direction of experimental one, in physical variables, weight and mass of fats. Where calculated value of " $T$ " is larger than its table one. Excepting for body weight, where there are statistically insignificant differences as calculated value of " $T$ " is less than its table value.

\section{TABLE (14)}

Value of (Eita) ${ }^{2}$ program effect and improvement percentage between premeasures and post-measures of experimental group in physical variables, weight and mass of fats. $(\mathrm{N})=\mathbf{1 0}$

\begin{tabular}{c|c|c|c|c|c|c|c}
\hline \hline \multirow{2}{*}{ Variables } & \multicolumn{2}{|c|}{ premeasure } & \multicolumn{2}{|c|}{ Post-measure } & \multirow{2}{*}{ Eita^2 $^{\text {Variation }}$} & \multirow{2}{*}{$\begin{array}{c}\text { percentage } \\
(\%)\end{array}$} & Direction \\
\cline { 2 - 9 } & Mean & St.Div & Mean & St.Div & & 0.02 & Premeasure \\
\hline \hline Fast power & 8.42 & 0.492 & 8.422 & 0.493 & 0.2 & 0.02 \\
\hline
\end{tabular}




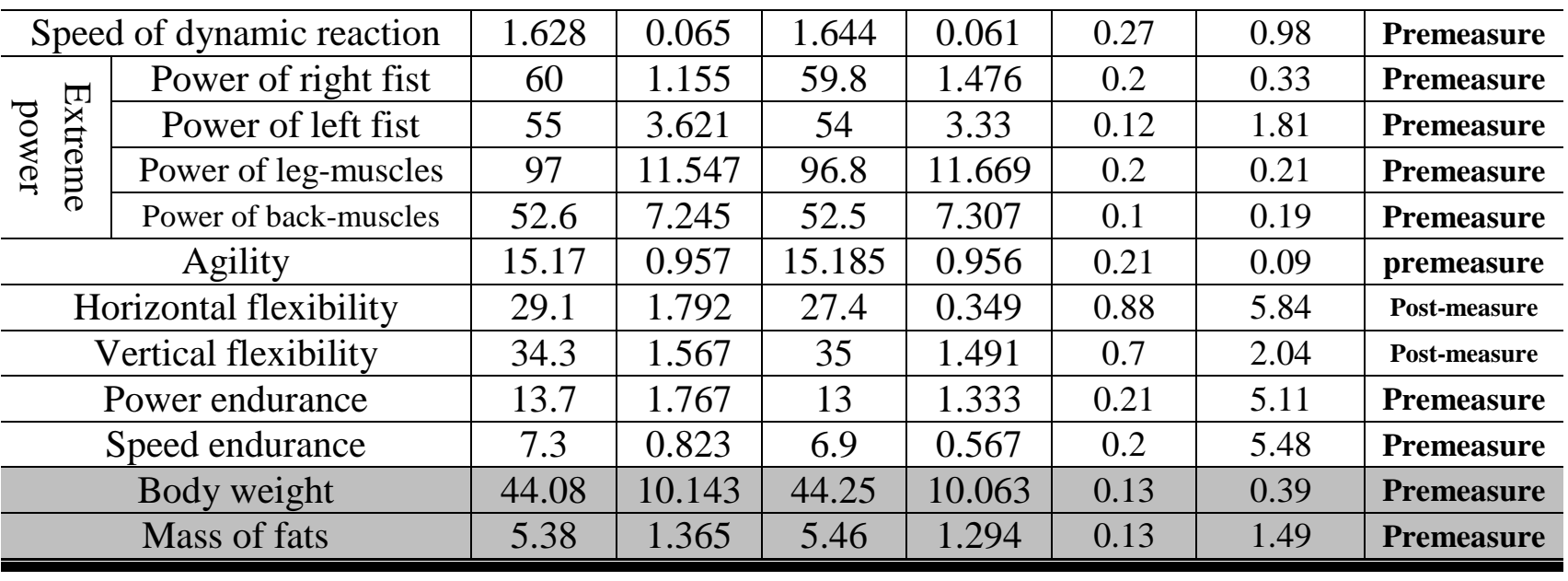

Results of table (14) indicate that value of (Eita^2) has ranged from( 0.1 to 0.88 ).

Variation percentage has ranged from $(0.02 \%$ to5.84\%),

\section{Grade for Eita`2: $^{\wedge}$}

(From (0) to less than $0.3=$ weak effect)

(from 0.3 to less than $0.5=$ Medium effect)

(From 0.5 to one $=$ strong effect)

\section{DISCUSSION OF RESULTS}

In accordance with previously stated results reached by researcher, and as a part of objectives and hypothesis of research, and guided by previous studies and content of scientific references, researcher starts to discuss these results as the following:

Table (11) shows that there have not been any statistically significant differences between premeasures and post-measures of experimental group, in elements of fitness in tests of fast power, speed of dynamic reaction, fitness, ultimate power (power of right and left fists, power of muscles of legs and back), power endurance and speed endurance. These differences have been in direction of premeasure, where values of " $T$ " have been (1.5), (1.809), (1.5), (1.088), (1.5), (1), (1.567), (1.561) and (1.5) as well. For horizontal and vertical flexibility, there have been statistically significant differences between premeasures and post-measures of experimental group in direction of post-measure, where value of " $T$ " has ranged from (4.583) and (7.965). These values are larger than table value of "T", which has been (1.833) at freedom degree of (9). This goes back to the training program, which contained flexibility exercise as one of the most important constituents. It is considered a main element of fitness, moreover, it is a preventive element vital to protection against sporting injuries and muscle ruptures.

Osman Refaat (2003) states that one should do flexibility exercise everyday through suitable training, and we should start with junior players (26:45).

In addition, table (11) shows that there have not been any statistically significant differences between premeasure and post-measure of experimental group in mass of fats and body weight. Calculated value of " $\mathrm{T}$ " for experimental group has ranged from (1.177) to (1.188). Therefore, it is less than table value of "T" which has been (1.833) at freedom degree of (9). This indicates that proposed program using cross method has led to maintain physical level, weight and mass of fats acquired through sports season. This agrees with Ali Al Saeed Farhan (2003)(7), quoting 
what has been said by Musaad Ali Mahmoud, that weight of a player maintains in a relative stability, when intake calories equal consumed ones, and in case players commit to instructions. This also agrees with Ali Fahmy Al-Bek et al. (2009), that transition period aims to restore recovery of vital organs of a player, from the effect of extreme physical and nervous exertion of training loads for both periods of preparation and competition, in addition to upgrading kinetic features and reducing physical level of a player, with the relative retention of training status, so as for a player to guarantee an optimal readiness for the next season. (8:123).

It also agrees with Musaad Ali Mahmoud (1997) that a transition period maintains development levels acquired through comprehensive preparation throughout the previous training season. Continuity of training in this period leads to avoiding excessive weight (24:201).

Table (14) shows values of (Eita)2 indicating that the program has strongly affected elements of fast power, speed of dynamic reaction, fitness, ultimate power (power of right and left fists, power of muscles of legs and back), power endurance and speed endurance. These values have ranged from (0.1 to 0.27), i.e. less than 0.5. This has been an evidence on that the proposed training program has not affected weight of players positively or negatively, instead it has relatively maintained their physical level and weight. Training program has contained variable exercises which differ from wrestling skills and matches as possible, and are characterized by passion and amusement, such as competitive small games, double training by body weight (lifting, pull and push), rope climbing, climbing net, rope jumping, swimming exercises, water games, general flexibility exercises, weight lifting using dumbbells, power exercises using rubber, belometric training on strips, Gymnastics (ground device, parallel device, horizontal bar, ring device and American football), football, basketball and long-distance running, with flexibility in applying game rules. Exercises designed by researcher have positively affected physical abilities being studied, in addition to weight and mass of fats, where researcher has taken into account scientific principles. This has highly affected stability of these variables. Value of (Eita) ${ }^{2}$ (program effect strength) for horizontal and vertical flexibility has ranged from ( 0.7 to 0.88 ). This goes back to the training program, which contained flexibility exercise as one of the most important constituents. It is considered a main element of physical fitness, moreover, it is a preventive element vital to protection against sporting injuries and muscle ruptures.

This agrees with Mohammed Bereikie and Ihab Al Bedeiwy (2004) that cross training programs in transition period of sporting season help players to maintain power and aerobic endurance, through doing many activities such as running, rope jumping, weight-lifting exercise and variable resistances (21:9).

Khaled El-Sayed Soroor and Mohammed Ibraheem Gadel-Haq (2008)(20) assure that using cross training with its different activities characterized by passion and amusement leads to reduce losses in physical fitness during the transition period. This is supported by that cross training helps all sporting levels to maintain weight and the maximum level of fitness. It helps to add variation to action, resulting in amusement. Therefore, traditional exercises can be used such as running, swimming, exercising using different equipment and skiing. It helps to distribute loads of training 
on different parts of the body, and thus reducing danger of injuries. It also helps to continue training during periods of injuries as one can use different muscles and joints, if a certain part has an injury (33)(34)(35).

These results are supported by percentage of variation, where results of table (14) indicate percentage of variation between premeasures and post-measures of experimental group in variables of physical fitness being studied, in direction of premeasure, where percentage of variation for different variables has been as the following: Fast power $0.02 \%$, Speed of dynamic reaction $0.98 \%$, Power of right fist $0.33 \%$, Power of left fist $1.81 \%$, Power of leg-muscles $0.21 \%$, Power of backmuscles $0.19 \%$, Agility $0.09 \%$, Horizontal flexibility $5.84 \%$, Vertical flexibility $2.04 \%$, Power endurance $5.11 \%$, Speed endurance $5.48 \%$, Body weight $0.39 \%$, Mass of fats $1.49 \%$

Values of horizontal flexibility and vertical flexibility have been $5.48 \%$ and $2.04 \%$ as well. Percentage of variation between premeasures and post-measures has been in direction of post measures

This shows that proposed program using cross method has led to relatively maintain level of physical abilities and weight being studied. Physical level hasn't been affected badly and weight has not been increased seriously. Osman Refaat (2003) states that one should do flexibility exercise everyday through suitable training (16:45).

These results agree with studies made by Yase Abdel-Azeem, Khaled Saeed El-Naby (1999)(31), Ali El Saeed Raihan (2003)(7), Ihab Mohammed Fawzy El Bedeiwy (2004)(17), El Sayed El Sayed Sa'd El Sayed (2005)(14), Hamdi Ibraheem Yahia (2005)(16), Mohammed Hamed Shaddad (2006)(22), Waseelah Mohammed Mahran (2007)(29), Khaled El Sayed Soroor and Mohammed Ibraheem Gad-El Haq (2008)(20).

Table (12) shows that there have been statistically significant differences between premeasures and post-measures of control group for premeasure of variables of physical fitness being studied, weight and mass of fats, in direction of premeasure, in tests of fast power, speed of dynamic reaction, fitness, ultimate power (power of right and left fists, power of muscles of legs and back), power endurance and speed endurance. These differences have been in direction of premeasure, where values of " $T$ " for the control group have been (21.423), (14.08),(11), (9.261), (8.515), (4.892), (5.461),(3.706), (6.866), (6.866), (8.51),(31.23)1 and (14.085) as well. These values are larger than table value of "T" which has been (1.833) at freedom degree (9). This shows that training stoppage during transition period has led to significant reduction in level of physical fitness and an increase in weight.

This agrees with Ihab El Bedeiwy (2004)(17), that training stoppage has led to a significant reduction in many physical variables. This has badly affected sporting performance. He also states, quoting what has been said by Hammer, that without using a program to maintain physical level through transition period, performance is reduced.

This also agrees with Ali Raihan (2003)(7), that reduction in constituents of physical fitness, resulted from training stoppage, goes back to neglecting adaption level reached by a player during regular-training period in addition to training 
stoppage, eating food as or more than usual. This increases intake calories and weight as a result.

Abdel-Azziz Al Nemr \& Nareman Al Khateeb (2005), Brent (1991) et al. assure that effects resulting from training stoppage for players of competitive sports highly-depending on muscular power result in loss of physiological adaption that has been built through regular training for long periods (1:250).

Results agrees with Abul-Ella Abdel-Fattah (1995), that training stoppage results in gradual weakness of muscles and loss of flexibility, leading to difficulties in moving joints to its full extent. In case a player stops training, he will begin to lose aerobic and anaerobic abilities $(6: 185,227)$.

Owees Al Gebaly (2000) states that if a player loses his physical fitness during transition period, it will be difficult to get it restored in a short time. Accordingly, a player becomes unable to start a new training course in a high level. Therefore, the transition period is the most suitable one to complete an annual training plan and to prepare to the next one (27:295).

Abul-Ella Abdel-Fattah (1995), Frank W. Dulk (1997) and Owees Al Gebaly (2000) see that in case a player doesn't make use of the transition period, he will be subjected to dangers of fatigue and boredom in the future, because of the overload. If a player stops training during this period, he will lose power within a week or two weeks. If this power loss continues, it will be negatively-reflected on performance. In case a player stops training for a month, he starts to lose aerobic and anaerobic endurance leading to level reduction. Losing these elements makes them difficult to be restored within a short time. Accordingly, a player becomes unable to start a new training course in a high level $(6: 61)(15: 83)(27: 295)$.

Table (13) shows that there are statistically significant differences between both premeasures of experimental and control groups in elements of variables of physical fitness being studied, weight and mass of fats, in direction of premeasure, in tests of fast power, speed of dynamic reaction, fitness, ultimate power (power of right and left fists, power of muscles of legs and back), power endurance and speed endurance. These differences have been for experimental group, where calculated values of "T" have been 5.21, 4.248, 5.262, 3.163, 1.828, 2.479, 3.778, 6.433, 3.285, $3.767,4.303$ and 3.028. Therefore, calculated value of " $\mathrm{T}$ " is larger than its table value at level (0.05). It is also larger than table value of " $T$ " that has been (1.734) at liberty degree (18). This shows that proposed training program has affected physical variables being studied in addition to mass of fats. In addition, there have been statistically insignificant differences between both experimental and control groups in post-measure of body weight, for direction of experimental group. Calculated value of " $T$ " $(0.879)$ has been less than its table value at level $(0.05)$, where masses of muscles, water and fats interfere in total body weight. Therefore, non-existence of statistically significant differences may have gone back to changing any of these variables.

Researcher sees that non-existence of statistically significant differences and existence of very small values of variation percentage, go back to the proposed training program using cross method applied to experimental group and its physical variables being studied. Training program has contained variable exercises which 
differ from wrestling skills and matches as possible, and are characterized by passion and amusement, such as competitive small games, double training by body weight (lifting, pull and push), rope climbing, climbing net, rope jumping, swimming exercises, water games, general flexibility exercises, weight lifting using dumbbells, power exercises using rubber, belometric training on strips, Gymnastics (ground device, parallel device, horizontal bar, ring device and American football), football, basketball and long-distance running, with flexibility in applying game rules. Exercises designed by researcher have positively affected physical abilities being studied, in addition to weight and mass of fats, where researcher has taken into account scientific principles. This has highly affected stability of these variables.

These results agree with studies made by Yase Abdel-Azeem, Khaled Saeed ElNaby (1999)(31), Ali El Saeed Raihan (2003)(7), Ihab Mohammed Fawzy El Bedeiwy (2004)(17), El Sayed El Sayed Sa'd El Sayed (2005)(14), Hamdi Ibraheem Yahia (2005)(16), Mohammed Hamed Shaddad (2006)(22), Waseelah Mohammed Mahran (2007)(29), Khaled El Sayed Soroor and Mohammed Ibraheem Gad-El Haq (2008)(20).

\section{CONCLUSIONS}

In accordance with objectives and nature of this study, and within limitations of research sample and method, and according to data and results of statistical analysis collected by researcher, researcher has concluded the following:

1. Proposed training program using cross method for experimental group has maintained physical variables being studied.

2. Proposed training program using cross method for experimental group has led to the existence of statistically significant differences between premeasure and postmeasure of horizontal and vertical flexibility of wrestlers, in direction of postmeasure.

3. Proposed training program using cross method has effectively-maintained body weight.

4. When control group stopped training during transition period, their physical abilities being studied had been reduced.

5. There have been statistically significant differences between both post-measures of control and experimental groups in physical variables being studied, in direction of experimental group.

6. There have been statistically significant differences between both post-measures of control and experimental groups in maintaining body weight, in direction of experimental group.

\section{RECOMMENDATIONS}

Within limitations of study's content of procedures and results, researcher recommends the following:

1. Applying proposed training program using cross method on junior wrestlers, so as to maintain their physical level.

2. Applying proposed training program using cross method on junior wrestlers, so as to maintain their body weight.

3. Training programs should be prepared during transition period to relativelymaintain sporting level. 
4. A wrestler should not stop training during transition period, in order not to be badly affected.

5. Using cross training method through other parts of the season to improve variables with shortages.

6. Using food programs which are suitable for each individual player and for physical activity.

REFERENCES

1 Abdel-Azziz Al (2005) Muscular power: Designing power programs and Nemr \& Nareman planning training season."Al Asatezah" for sports Al Khateeb

2 Abeer Khedr books.Giza.

(2011) Meal planning. Printing-house of Al Menofeya university for publication. Al Menofeya.

3 Abd El-fattah Fathi (1996) Reference of boxing."Al Maaref" Enterprise.

Khodeir

4 Abo El-ella Ahmed

Abdel-Fattah \&

Mohammed Nasr El

Din.

5

6

7 Ali El Saeed Rayhan

8 Ali Fahmy Al Bek \& others

9 Ali Fahmy Al Bek

10 Amr-Allah Ahmed El Bassaty

11 Anneta Ben

12 Brent S, Rushall \& Frank

13 Dietrich Harre

14 El Sayed El Sayed Sa'd El Sayed

\section{Frank.w Duk}

16 Hamdi Ibraheem Yahia
Alexandria.

(2003) Physiology of physical fitness "Dar Al Fikr Al Arabi",Cairo.

(1997) Sports training."Dar Al Fikr Al Arabi", Cairo.

(1995) Sports biology."Dar Al Fikr Al Arabi",Cairo

(2003) Effect of a proposed program for transition period on many constituents of physical fitness related to health of senior wrestlers. Magazine of sports and physical education sciences. Faculty of physical education. Al Mansoura university.

(2009) Modern trends in sports training - theories and applications."Al Maaref" Enterprise.Alexandria.

(1992) Principles of preparing football player and teamgame players."AL Tony" Printing house. Alexandria.

(1998) Principles \& applications of sports training. "Al Maaref" enterprise.Alexandria.

(2004) Complete food program for athletes."Dar Al Farouk" for publishing \& distribution. Cairo.

(1991) Training for sports and fitness, Macmillan comm. Hong Kong.

(2001) Principles of sports training, sport verlag, 3rd edition.

(2005) Cross training and its effect on many physical variables and digital achievement of swimmers in the transition period - published research - Magazine of sports and physical sciences. $8^{\text {th }}$ edition $-1^{\text {st }}$ folder.

(1997) Sports training principles, London

(2005) A program using cross training in transition period, and its effect on muscle power, flexibility and digital level of $100 \mathrm{~m}$ runners. Published 


\section{Ihab Mohammed} Fawzy El Bedeiwy

18 Ilham Ismael Ahmed Shalaby.

19 Kamal AbdelHameed \& AboelElla Abdel-Fattah \& Mohammed El

Sayed El Ameen

20 Khaled El Sayed

Soroor \&

Mohammed

Ibraheem Gad-El

Haq

21 Mohammed Gaber Breeqie \& Ihab Fawzy El Bedeiwy.

22 Mohammed Hamed Shaddad.

23 Mohammed Nasr El Din Radwan.

24 Musaad Ali Mahmoud

25 Nasr Abo Bakr Nasr Mohammed

26 Osman Hussein Refa't.

27 Owees Al Gebaly

28 Sami Moheb Hafez

29 Wasselah
research.Magazine of sports and physical sciences $-8^{\text {th }}$ edition $-1^{\text {st }}$ folder. Faculty of physical education. Al Menofeya University.

(2004) Effect of a program using cross method on physical and physiological variables, and the effectiveness of chest skrew for wrestlers.Published research - Scientific magazine $-1^{\text {st }}$ Folder. Faculty of physical fitness for girls. Helwan university.

(1994) Food information and its relation to physical configuration and performance of female-students.

Magazine of faculty of physical education for girls. Cairo.

(1999) Food for athletes."Al Ketab Center for publishing".Cairo.

(2008) Effect of using cross training on maintaining muscle fitness and power fitness through transition period of training season. $10^{\text {th }}$ Scientific conference of physical education \& sports sciences. Faculty of physical education for youth. Alexandria.

(2004) Cross training - principles - definitions applications"Al Maaref" Enterprise. Alexandria.

(2006) Effect of using cross training in transition period on improving physical performance of Judo players.Published research. Magazine of theories and applications. Faculty of physical education. Alexandria university.

(1997) Reference of physical measures."Dat Al Fikr Al Araby" Cairo.

(1997) An introduction to sports training science. "Dar Al Teba'a" for publishing and distribution. Al Mansoura university.

(1993) Effect of weight reduction on concentration of both salts of Sodium and Potassium in blood of wrestlers.Unpublished master thesis. Faculty of physical education for females. Helwan university.

(2003) Science of sports training. Unpublished research.

(2000) Sports training - Theory and applications.

G.M.C. house for printing and publishing.Cairo.

(2005) An Introduction to modern Boxing. Stationary "Shagarat al dor".Al Mansoura.

(2007) Effect of cross training in transition period on 
Mohammed Mahran many physical requirements, physiological variables and digital level of $400 \mathrm{~m}$ runners -published research. Magazine of theories and applications.Faculty of physical education for males. Alexandria university.

30 Yahia El Sayed

Ismael Al Hawy (1997) Boxing - principles - theories and applications. Arabic Publication center. Zagazeg.

Yaser Abdel Azeem (1999) Necessities for premeditated reducing of level of \&

31 Khaled Saeed Al Naby. training status from its physical side, while planning for transition training period for junior footballers.International conference for physical education: between theory and application. Faculty of physical education. Helwan university.

Zaky Mohammed (2004) Cross training: a modern trend in sports

32 Mohammed Hassan. training.Egyptian stationary for publishing and distribution.Alexandria.

33 http://www.or/thoinfo.org/fact/thr.report

34 http://www.physssportsmed.com/

35 http://www.runnersworld.com/

36 http://zera3h.blogspot.com/2011/04/blog-post3583.html 